\title{
Effect of Pyrolysis Temperature and Time of Liquid Smoke Product from Candlenut Shell by Pyrolysis Process
}

\author{
Sulhatun, Rosdanelli Hasibuan, Hamidah Harahap, Iriani
}

\begin{abstract}
The purpose of this research particularly to acknowledge process conditions that give the best yield of liquid smoke products maximum resulted during pyrolysis process of biomass shell pecans.

This Research conducted on a fixed batch reactor made of metal plate with a thickness of $3.0 \mathrm{~mm}$. It carries $200 \mathrm{kegs}$ in capacity. In this phase, the moisture of Candlenut shells might be kept in 10 - 12.5 wt. percentages. Process temperature variation in the temperature of $350^{\circ} \mathrm{C}, 450^{\circ} \mathrm{C}$ and $550^{\circ} \mathrm{C}$. and variations of pyrolysis at 15, 30, 45 until 435 min. Product identification by GCMS at Optimum condition to determine the components of pyrolysis generated.

The result of the research is the best process condition of liquid smoke during pyrolysis maximum of Candlenut shell by using pyrolysis method at the time of $210 \mathrm{~min}$ and $450 \mathrm{C}$ Temperatures respectively can be obtained maximum product yield of liquid smoke around $2.62056 \%$.

Identification of products by using GCMS (GC Mass Spectrometry) at optimum condition at temperatures of $450^{\circ} \mathrm{C}$. and pyrolysis time is 210 min showed that liquid smoke candle nut shell consist of 7 (Seven) components consist of Cyclopentanone, Cyclopenten1 2-one, 2-cyclopenten-1-one, Acetic acid, Furancarboxildehide 2, 2 and 2 methoxyphenol Methoxy-4- methyl phenol.
\end{abstract}

Keywords: Liquid smoke, Candlenut Shell, pyrolysis.

\section{INTRODUCTION}

Hazel Nut or Candle Nut (Aleurites moluccana) is classified as one of the huge available natural resources in Indonesia, being considered as a commodity wide marketing prospect either domestic and overseas. Candle Nut shell resulted from its plantations is claimed as one of numerous solid waste biomasses, containing organic compounds such as hemicelluloses, cellulose, and lignin. (Sulhatun, et.al, 2017),

Revised Manuscript Received on October 15, 2019.

* Correspondence Author

Sulhatun, Student of Doctoral Program in Chemical Engineering Department, Faculty of Engineering, University of North Sumatra, Medan, North Sumatera, Indonesia.

Rosdanelli Hasibuan, Lecturer of the Doctoral Program in Chemical Engineering Department, Faculty of Engineering, University of North Sumatra, Medan, North Sumatera, Indonesia.

Hamidah Harahap, Lecturer of the Doctoral Program in Chemical Engineering Department, Faculty of Engineering, University of North Sumatra, Medan, North Sumatera, Indonesia.

Iriani, Lecturer of the Doctoral Program in Chemical Engineering Department, Faculty of Engineering, University of North Sumatra, Medan, North Sumatera, Indonesia.

Utilizing waste of biomass as the source of liquid smoke thorough pyrolysis are commonly used, thus by using several such raw materials like coconut shells [2], palm stems, empty fruit bunches of palm [3], palm shell, saw dust, straw, wheat, grass [4],, pine nut shells [5],, atrophy seeds, Niger seeds Karanja [6], pine woods, corn cob [7], date seeds, coconut husks, plum seeds and waste residue. However, making a liquid smoke-based solid waste walnut shell is rarely done when solid waste walnut shell has a characteristic organoleptic content, as a potential raw material for the manufacture of liquid smoke. Efforts to use shell pecans through the concept of recycle, reuse and recovery will provide benefit for hazelnut growers in Indonesia. Thermal decomposition that occurs in shell pecans produce liquid smoke which has organoleptic properties as shell pecans have a composition similar to the composition of the other biomass.

In the pyrolysis process, shell pecans will have to solve the structure of the chemical in the process of hydrolysis, primary decomposition, repolarization influenced by process conditions and raw materials, it is a major problem in the products of pyrolysis. Types of raw materials affect product composition and characteristics of PAHs are formed. The content of PAH compounds are formed require the development process further after the pyrolysis process is carried out to produce liquid smoke purely composition and products better.

Pyrolysis resulted biomass by means of thermal degrading in high temperature upon raw materials in a reactor is isolated from the atmosphere or oxygen, whereas liquid products in the range of $30 \% \mathrm{w}$ up to $70 \%$ w yielded averagely. Pyrolysis also known as thermo-chemistry technology to convert biomass to energy sources on and other chemical products comprising of liquid organic oil, organic pyrolysis gases and ash. Several parameters applied on pyrolysis influencing characteristics and applications of these products, 
i.e. selecting in the type of raw materials (biomass kinds, particle sizes, pretreatment of biomass, the reaction's conditions (temperature, pressure, particles heating rate and contact durations), reactor configuration applied, due process and other variables such us extending catalysts and vapor condensing mechanism. Characteristic of pyrolysis products consisting of liquid smoke as a prime product, bio-char as a solid-state product, Tar, and gas resulted. [7] [8]. [1]

Liquid smoke has the potential for use an all-natural antimicrobial in commercial application where the smoke flavor is desired, use in food application [9] because liquid smoke has benefits as ant oxidative and anti-microbial. [10]. the smoking of meat, has been used as preventative a technique for centuries [11]. Redistills liquid smoke from Shell Oil palm has been proven effective as a preservative fresh fish due to its antibacterial activity. [12] Latex coagulant is one of the important factors on natural rubber because it will determine the quality of rubber product. One of the coagulants is that produce good quality natural rubber is liquid smoke. [15].

The purpose of this research was to determine the pyrolysis products produced using alternative materials such as walnut shells for the production of liquid smoke and determine the best process conditions at each stage of the process that yields the maximum.

\section{EXPERIMENTAL}

\section{Collection and Preparation of Raw Material}

Stage of raw materials, which include raw material preparation shell pecans from the pecan plantations, which are in North Aceh district. Drying it under the sun for 2-3 days to maintain water levels of $10-13 \%$. Then phase process includes the decomposition thermal done pyrolysis using fixed Batch Reactor temperature was varied at 350, 450, 550 ${ }^{\circ} \mathrm{C}$ and a pressure of 1 (one) atmosphere and the pyrolysis 15 , 30,45 , up to and 435 minutes and the temperature of the condenser range $25-40{ }^{\circ} \mathrm{C}$. Next Level Analysis perform analysis on product yield of liquid smoke produced from the process of identification and pyro Lisa components contained in the liquid smoke on condition.

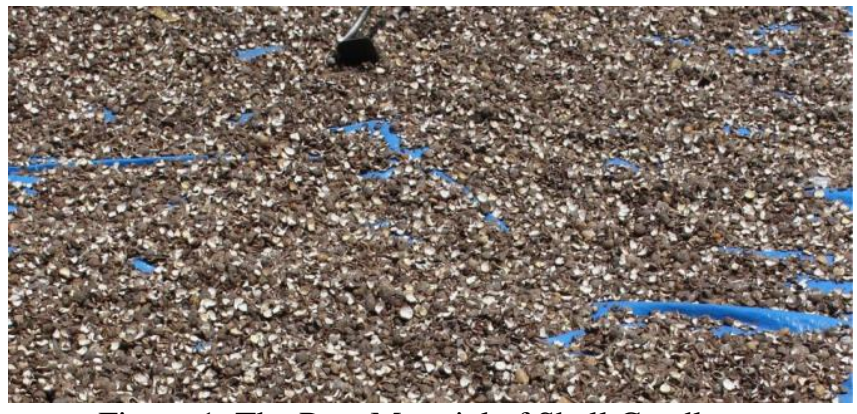

Figure 1. The Raw Material of Shell Candlenut
The reactor design is in a batch reactor with capacity of $300 \mathrm{~kg}$ and $200 \mathrm{~kg}$ working volume with the temperature of the cooling water at the condenser pyrolysis $\left(28-35^{\circ} \mathrm{C}\right)$. , Condenser temperature is kept at a temperature of 25 to $30 \mathrm{C}$ to regulate the flow rate of water condensation in and out. Geochemical equipment to be used is the Double Unit Condenser Process temperature is varied at 350, 450, and $550^{\circ} \mathrm{C}$ and Time of pyrolysis presets i.e. $15,30,45,60$ and 425 minutes. In the process of condensation, the condenser is connected with the pyrolysis into one network. Gas or condensate

Produced from the pyrolysis reactor out of the pipe is connected to the condenser serves to change the gas phase pyrolysis product gas into the liquid phase. Condenser apparatus used is equipped with two (2) unit's condenser system that paralleled to increase the condensation products of pyrolysis as possible. Furthermore, the products collected into the storage tank the product resulting from the process pyro Lisa for more details can be seen in Figure 2 where the pyrolysis product consists of liquid smoke as the main products, coal, and tar as a byproduct and a non-condensable gas.

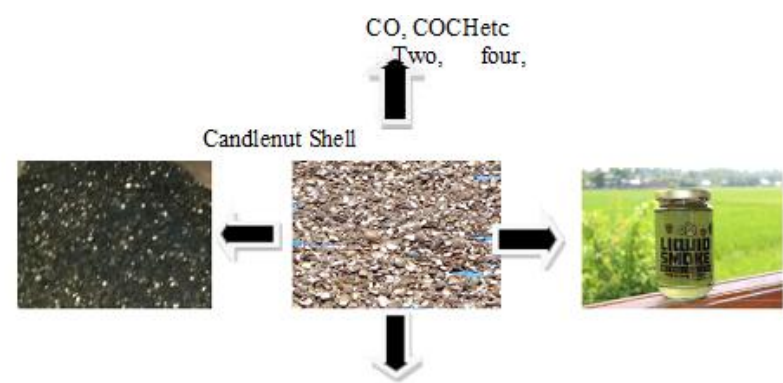

The Char of CNS

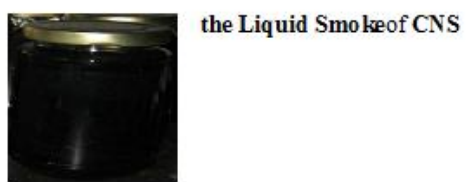

Tar

Figure 2: The product of the process of pyrolysis candle nut shell biomass

\section{Analytical Products}

Analysis of liquid smoke by measuring the volume of liquid smoke produced in a measuring cup during a time interval of pyrolysis is performed at each temperature used. Furthermore, the calculation of the percentage of the product liquid smoke produced from the condensation process can use the equation with the following formula:

Yield Liquid smoke r $(\%)=$ Weight of Liquid smokex $100 \%$ Weight of Candlenut shell

The next step is to identify the products by using GCMS (GC Mass Spectrometry). Calibration of area Chromatograph to be done by analyzing the response factors over which the chemical

\section{Process pyrolysis}


group appearances firstly determined by using a mix of standard and reference compounds (for liquid Tetra line for methane gas) with a very concentrations.

Unidentified peaks of chromatograph, figures for coverage of a $5 \%$ of the total area, presented by average response factor. Characteristic of liquid products may observed by using Carlo Elba EA 1108 that equipped with micro Elemental analyzer. By this instrument, a liquid smoke-water mixture can be observed (Carl Fische Technic, IRAM 21320). Calorie value of liquid

The schematic diagram of Candlenut Shell pyrolysis process using a fixed batch reactor can be seen in Figure 3 below:

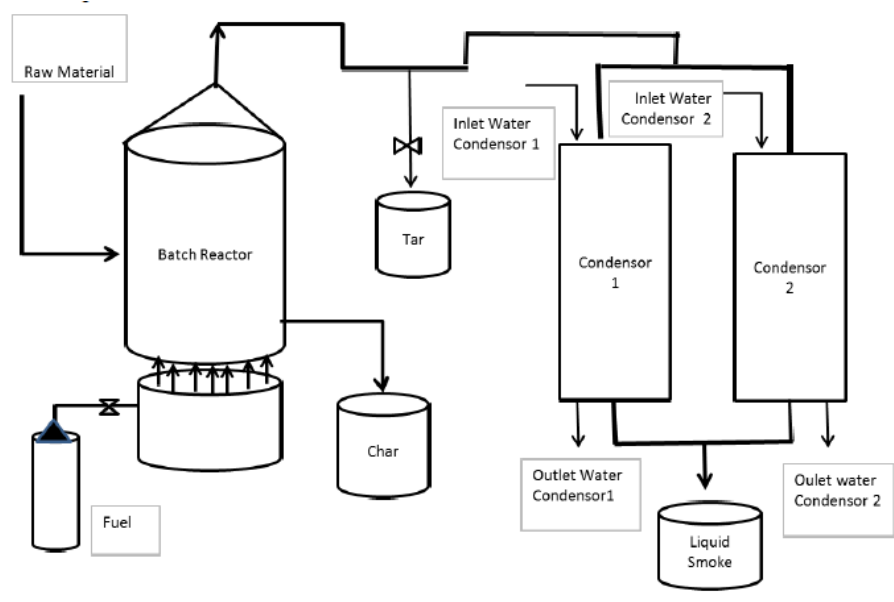

Figure 2: The schematic diagram of Candlenut Shell pyrolysis process using a fixed batch reactor system double condenser unit

\section{RESULT AND DISCUSSION}

The analysis results of Liquid smoke Table 1 shows that the amount of liquid smoke at the parameters of the process of the pyro Lisa shell pecans.

Table 1 of liquid smoke product of pyrolysis shell pecans

\begin{tabular}{|c|r|r|r|}
\hline \multirow{2}{*}{$\begin{array}{c}\text { Time } \\
\text { Minutes) }\end{array}$} & \multicolumn{3}{|c|}{ Products Liquid Smoke (\%) } \\
\cline { 2 - 4 } & $\begin{array}{c}\text { Temperature } \\
\mathbf{3 5 0}{ }^{\circ} \mathbf{C}\end{array}$ & $\begin{array}{c}\text { Temperature 450 } \\
{ }^{\circ} \mathbf{C}\end{array}$ & $\begin{array}{c}\text { Temperature 550 } \\
{ }^{\circ} \mathbf{C}\end{array}$ \\
\hline 15 & 0,09763 & 0,12846 & 0,12332 \\
\hline 30 & 0,23123 & 0,40593 & 0,37253 \\
\hline 45 & 0,22609 & 1,03281 & 0,84526 \\
\hline 60 & 0,32885 & 1,23320 & 1,03538 \\
\hline 75 & 0,37510 & 1,25890 & 1,06621 \\
\hline 90 & 0,55237 & 1,59289 & 1,10731 \\
\hline 105 & 0,64229 & 1,64427 & 1,09190 \\
\hline 120 & 0,82727 & 1,95257 & 1,10475 \\
\hline 135 & 0,91206 & 2,00396 & 1,26146 \\
\hline 150 & 0,87352 & 2,04249 & 1,30000 \\
\hline 165 & 0,93775 & 2,08103 & 1,66996 \\
\hline 180 & 0,97629 & 2,09388 & 1,92688 \\
\hline 195 & 1,01482 & 2,53064 & 2,22234 \\
\hline $\mathbf{2 1 0}$ & $\mathbf{1 , 3 4 8 8 2}$ & $\mathbf{2 , 6 2 0 5 6}$ & $\mathbf{2 , 0 2 4 5 1}$ \\
\hline 225 & 1,25890 & 2,31226 & 1,71621 \\
\hline 240 & 1,22036 & 2,00396 & 1,64941 \\
\hline 255 & 1,25890 & 1,96542 & 1,74961 \\
\hline 270 & 1,16897 & 1,81898 & 1,69566 \\
\hline 285 & 1,07905 & 1,78558 & 1,42846 \\
\hline
\end{tabular}




\begin{tabular}{|r|r|r|r|}
\hline 300 & 1,05336 & 1,54151 & 1,15613 \\
\hline 315 & 1,10475 & 1,41305 & 1,23320 \\
\hline 330 & 1,01482 & 1,13044 & 0,95059 \\
\hline 345 & 0,66799 & 1,02767 & 1,02767 \\
\hline 360 & 0,91206 & 0,98913 & 0,89921 \\
\hline 375 & 0,57806 & 0,97629 & 0,80929 \\
\hline 390 & 0,55237 & 0,77075 & 0,70652 \\
\hline 405 & 0,66799 & 0,83498 & 0,74506 \\
\hline 420 & 0,52668 & 0,80929 & 0,74506 \\
\hline 435 & 0,46245 & 0,77075 & 0,69368 \\
\hline Total & $\mathbf{2 2 , 8 7 0 8 0}$ & $\mathbf{4 2 , 7 7 1 6 3}$ & $\mathbf{3 4 , 3 5 7 5 8}$ \\
\hline
\end{tabular}

\section{Effect of s temperature and time of pyrolysis on production of liquid smoke}

Results using pyrolysis done with varying conducted to determine the effect of pyrolysis to produce liquid smoke produced. At this stage, the pyrolysis is carried out with 15 minutes to 435 minutes with an interval of 15 minutes. Then also carried a variation of the temperature pyrolysis ${ }^{\circ} 350$, $450,550 \mathrm{C}$ with a capacity of raw materials is still $200 \mathrm{~kg}$. Smoke generated will liquidize tube condenser results can be seen in IMAGE3 following:

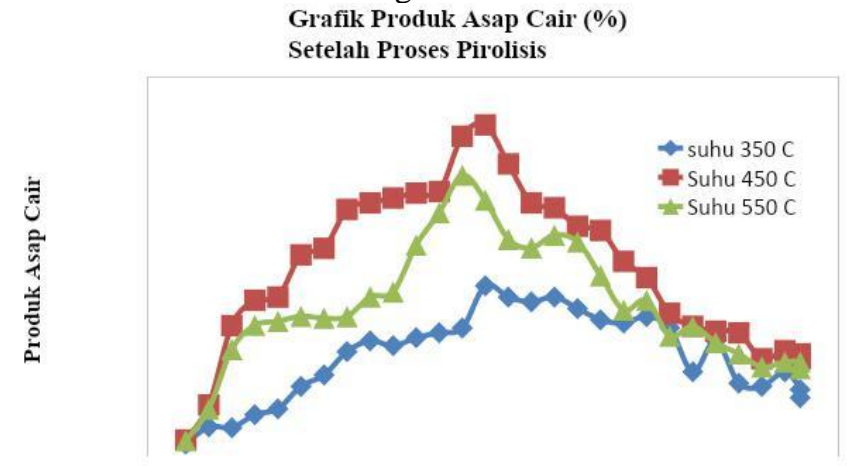

Figure 4. Relationship Graph percentage of liquid smoke to the time and temperature

Data from the experimental results and the graph above shows that the effect on the pyrolysis of the resulting product where the rate increased over time, and the longer the time of the volume of pyrolysis liquid smoke, visible liquid smoke that rate increases dramatically as the beginning of the pyrolysis process and the long time it pyrolysis percentage of the product decreases. The highest percentage of the product occurs at the time pyrolysis 210 minutes at a temperature of 450 pyrolysis ${ }^{\circ} \mathrm{C}$ is equal to $\mathbf{2 . 6 2 0 5 6 \%}$ and is followed by the percentage of the product at the same time but at a temperature of $550{ }^{\circ} \mathrm{C}$ at $\mathbf{2 . 0 2 4 5 1 \%}$, while the suhu $3500^{\circ} \mathrm{C}$ as the lowest temperature liquid smoke product maximum at the same time of $1.34882 \%$. Thus, the optimum product yield percentage is highest in the pyrolysis 210 minutes with the best temperature of $450{ }^{\circ} \mathrm{C}$. That time has an effect on the production process but also influenced by other factors, such as temperature pyrolysis. The interaction of these two factors led to the synergy effect of accelerating the formation of a product gas from biomass material composition process of shell pecans, while the percentage of products also affected the process liquidation gas composition happens in the process of the composition condenses. Then perfect due to the heat is distributed more evenly in the reactor so contact with hot material can increase the rate of production.

When the process of pyrolysis, there are several stages of decomposition of biomass material shell pecans is in the early stages of the process of evaporation of water first followed by the decomposition of biomass material such Hemicellulose, lignin and cellulose that produce gas lighter $\mathrm{CO}$ and $\mathrm{CO}$ and water discharge $\mathrm{CO}$ decomposition occurs high range of $15 \mathrm{~min}$ to 435 minutes with 15 -minutes intervals over the process. Then followed the process of decomposition of hemicellulose, cellulose, and lignin. At the time, the temperature reaches the range of $350^{\circ \mathrm{C}}$ to $550^{\circ \mathrm{C}}$. The product formed when this is tar. According to Girard (1992) all the decomposition of biomass to evaporate along with the rising temperature pyrolysis and the pyrolysis residue is left on the charcoal pyrolysis temperature of $450^{\circ} \mathrm{C}$ to produce compounds that have a high quality, organoleptic and at higher temperatures again.

Temperature is one of the most influential liquid smoke production parameters [8] [10] [12].

From the graph showing the relationship of the percentage of liquid smoke made by pyrolysis temperature used. Effect of Temperatur on yield liquid smoke production

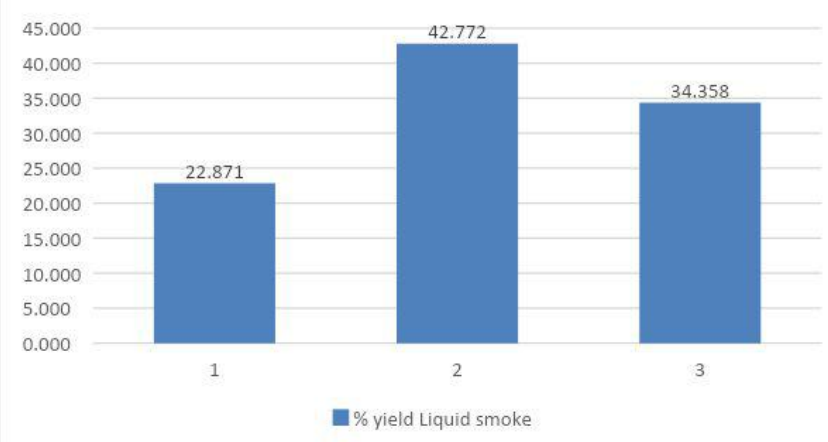

Figure 5: Effect of Temperature yield on liquid smoke production 
By five image above can be seen that the process temperature pyrolysis the lowest percentage of pyrolysis of $22.87080 \%$ of the total number of products pyrolysis. While products are produced at a temperature of $450{ }^{\circ} \mathrm{C}$ is equal to $42.77163 \%$ of the total product of liquid smoke largest, while the maximum temperature of $550^{\circ} \mathrm{C}$ product liquid smoke produced decreased by the amount of liquid smoke product is $34,35758 \%$.

\section{CONCLUSION}

From this research conclusion can be described as followers the best process condition of liquid smoke during pyrolysis maximum of Candlenut shell by using pyrolysis method at the time of $210 \mathrm{~min}$ and $450 \mathrm{C}$ Temperature respectively can be obtained maximum product yield of liquid smoke around $2.62056 \%$.

Identification of products by using GCMS (GC Mass Spectrometry) at optimum condition at temperatures of $450^{\circ}$ C. and pyrolysis time is $210 \mathrm{~min}$ showed that liquid smoke candle nut shell consist of 7 (Seven) components consist of Cyclopentanone, Cyclopenten 1 2-one, 2-cyclopenten-1-one, Acetic acid, Furancarboxildehide 2, 2 and 2 methoxyphenol Methoxy-4-methylphenol.

\section{ACKNOWLEDGMENTS}

The authors to respect and thanks to the Department of Research and Technology of Indonesia and the Directorate Kemenristek who have contributed and supported in financial upon this research there bye accomplishing this research accordingly.

\section{REFERENCES}

[1] Sulhatun, Rosdanelly H., H. Hamidah, Ariani,"Improving production of Liquid Smoke from Shell Candlenut By pyrolysis sprocess. Emerald REACH Proceeding Series, 2017, Vol 1, pp 141-147DOI10.1108978-1-78756-793-1-00056

[2] Darmadji Moon (2012), "Optimization of Liquid Smoke Purification by Encapsulation of Coconut Shell Liquid Smoke in Chitosan - Maltodextrin based nanoparticle, 173-179

[3] Jemaa Mabrouk, Mohamed Ammar Abbassi, Guedri Kamel, Ahmed Omri, and Mejdi Jeguirim, (2015) "Simulation of biofuel production via fast pyrolysis of palm oil residues" Fuel 159 (2015) 819 -827

[4] Dengyu Chen, Chen Xiaojuan, Sun Jun, Zheng Zhongcheng, Kexin and $\mathrm{Fu}, 2016$, pyrolysis polygeneration of pine nut shell: Quality of pyrolysis products and study on the preparation of activated carbon from biochar page 629-636

[5] Krishna Prasad Shadangi et.al. 2015, Krushna Prasad Shadangi, Kaustubh Mohanty, 2015 Co-pyrolysis of Karanja and Niger seeds with waste polystyrene to produce liquid fuel, Fuel 492-488

[6] Jiacheng Shen, C. Igathinathane, Sanlu Yu, Anand Kumar Pothula (2015) Biomass pyrolysis and combustion reaction anddifferential integral seat with temperatures using Thermogravimetric analysis / differential scanning calorimetry. Page 89-98.

[7] Wei-Hsin Chen, Bo - Jhih Lin, 2015, Characteristics of products from the pyrolysis of oil palm fi ber and its pellets in nitrogen and carbon dioxide atmospheres., Energy 94, 569-578

[8] AV Bridgwater, 2010, review of fast pyrolysis of biomass and product upgrading, biomass and Bioenergy 38, 68-94

[9] Steven C. Ricke and Philip G. Crandall, 2014 "Fucntionally of Liquid Smoke as an all-natural antimicrobial in food preservation" Meat Science $97197,2016$.

[10] Chen, WH and Jhih Lin, B., 2015. Characteristics of products from the pyrolysis of oil palm fi ber and its pellets in nitrogen and carbon dioxide atmospheres. Energy. 94: 569-578.

[11] Satrijo Saloko, Moon Darmadji, Bambang Setiadji, Yudi Pranoto "2014," antioxidative and antimicrobial activies of Liquid smoke nanocapsule using chitosan and maltodextrin and its application on tuna fish preservation. "Food Bioscience 7, 71-79
[12] Tao Kan, Vladimir Střezov, Tim J, Evans, 2015, lignocellulosic biomass pyrolysis: A review and effects of pyrolysis parameters "Renewable and Sustainable reviews 57, 1126-1140

[13] SS, Achmady, NR Mubarik, Rony and Septiaji" 2013 "Characterization redistilled of Liquid Smoke of

[14] Oil - Palm Shell and its Application as fish preservatives "Journal; of Applied Science 13, 401-408,

[15] Afrizal fahlepy \& Book Suwardi, 2015, "Characterization of iron metal corrosion in liquid smoke-coagulant, International Symposium on Chemistry aplied 2015 (ISAC 2015), Procedia Chemistry 16, SSS420-426 